\title{
Influence of Genetic Variation in Oak Leaf Roller Pupae and Their Host Plants on Body Sizes of Their Parasitoids, Itoplectis maculator (Fabricius, 1775)
}

\author{
Andrey Simchuk and Anatoly Ivashov \\ Department of Ecology, Taurida National V.I. Vernadsky University, Vernadsky Avenue 4, 95007 Simferopol, Ukraine
}

Correspondence should be addressed to Andrey Simchuk, ecology@crimea.edu

Received 3 November 2010; Revised 15 March 2011; Accepted 11 April 2011

Academic Editor: G. B. Dunphy

Copyright (C) 2011 A. Simchuk and A. Ivashov. This is an open access article distributed under the Creative Commons Attribution License, which permits unrestricted use, distribution, and reproduction in any medium, provided the original work is properly cited.

\begin{abstract}
Variation in sizes of parasitoids Itoplectis maculator F. (Hymenoptera, Ichneumonidae) were studied in respect to their genetic variation as well as to the genetic variations in their host insect (Tortrix viridana L.) pupae and their host plant (Quercus pubescens Willd). The data obtained have shown that the interactions between genotypes of parasitoids and their host insects contribute up to $49 \%$, and interaction between genotypes of parasitoids and oaks contributes up to $28 \%$ to the total variation in the parasitoid body sizes. As the parasitoid body size is fitness related, we may conclude that fitness of a parasitoid depends on not only its genotype but also on genotypes of its host insects and even the tree on which the host insects have developed. As a result the genotypes of representatives of the studied food chain links were found to be stochastically associated.
\end{abstract}

\section{Introduction}

Throughout the 20th century, investigators sporadically attempted to incorporate genetics into ecological explanations [1]. These attempts developed ecological genetics and evolutionary ecology, which complete each other with first studying genetic responses to ecological influences, and second examining their evolutionary consequences. In genetic sense, both of them operate at the scale of populations, addressing attention to their gene pools.

Recent investigations concerning interplay between genetics and ecology raised a question on foundation of a new field of enquiry "community genetics" [2-4], usefulness of which was discussed in the Special Feature (Ecology, 2003, vol. 84, no. 3). Commenters on the papers by Neuhauser et al. [2] and Whitham et al. [3] did not reject the importance of the obtained results, but expressed certain skepticism to some of their conclusions and insights. Negative reaction was evoked by use of such terms as "community heritability" and "community selection," which, by opinion of some authors $[5,6]$, resurrects the apparently irrepressible idea of the com- munity as superorganism $[7,8]$, long ago rejected by most ecologists after decades of empirical study and argument $[9,10]$. Some authors argued that Neuhauser et al. [2] and Whitham et al. [3] have not provided a compelling argument that the community genetics perspective is fundamentally different from the current emphasis of much of ecological genetics and evolutionary ecology [5].

Community genetics, by our opinion, should address its attention to the gene pools of the populations, which interact in a community, discovering the situation when alteration in gene pool of one population evokes corresponding alterations in another one. Such situation may arise only in that case when the fitness of a specimen depends on the kind of another species representative, with which it interacts in a community.

Direct estimation of specimen fitness is a difficult task if possible at all. One of the useful ways lies in measurement of quantitative signs related to average fitness, such as body sizes in insects $[11,12]$. The paper, thus, is focused on the study of variation in body sizes of parasitoids Itoplectis maculator Fabricius, 1775 (Hymenoptera, Ichneumonidea) in respect 


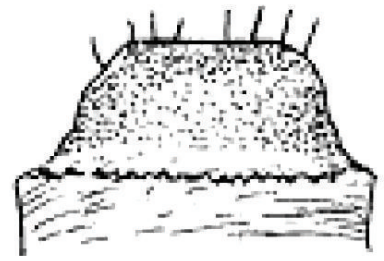

1

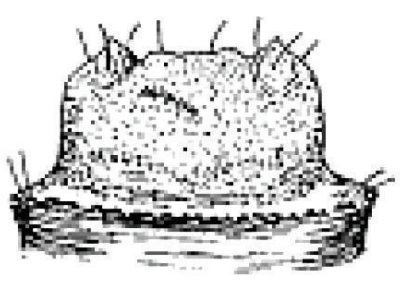

5

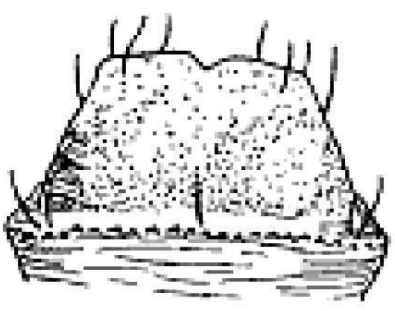

2

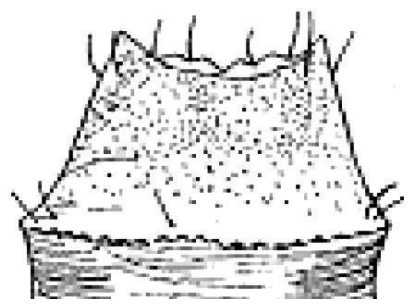

6

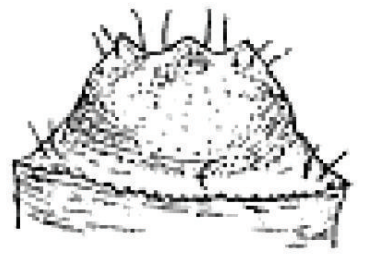

3

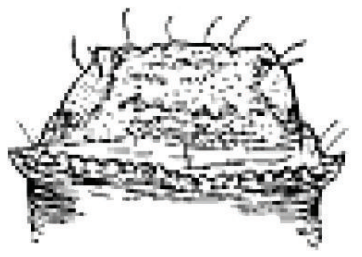

7

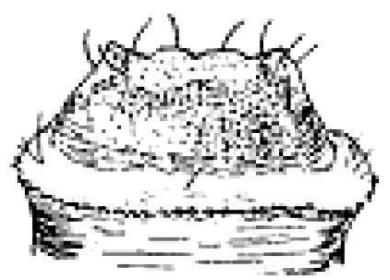

4

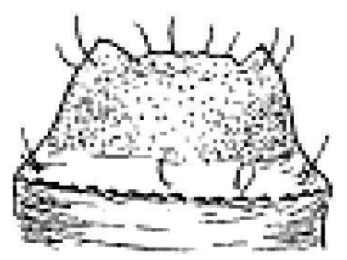

8

Figure 1: Variants of the T. viridana L. pupae cremasters with 1-8 peaks at their tops [14].

to their genetic variation as well as to the genetic variations in their host insect (Tortrix viridana L.) and its host plant (Quercus pubescens Willd).

\section{Material and Methods}

The material was collected in the T. viridana population named "Lavrovoe" (chaparral on southern coast of Crimean peninsula near Yalta). The leaf roller pupae were sampled from 14 trees of pubescent oak (Quercus pubescens Willd) (about 80 pupae per tree, 1142 in total). We choose the trees from the same locality, as close as possible each from other, to minimize influence of secondary factors, such as climate, soil, and so forth, and address main attention to their genetic heterogeneity. High gene flow among the parasitoid micropopulations on the trees minimize local effects, and variation in sizes of the parasitoids should reflect variation in their fitness components during the period from egg laying to adult emergence. We, thus, had a natural experiment when more or less homogenized mixtures of genetically distinct $I$. maculator specimens were placed in environments created by genetically distinct leaf rollers or oaks.

Each pupa was placed in separate vial and stored under the laboratory conditions. The vials were then daily inspected in respect to emergence of adults or parasitoids. Some of parasitoids from each of the trees were placed in liquid nitrogen until analysis.

Genetic variation in the oak leaf roller pupae was studied using morphological alternative signs as genetic markers [13]. We studied following leaf roller signs [14]: pupa color with variants: brown (1) and black (2); the number of peaks at the pupa cremaster from 1 to 8 (Figure 1). Pupae with 2 and 4 peaks at their cremasters were most common and presented in all the samples while other variants were rare, and, as they were absent in some samples, we excluded them from the analysis.

The emerged parasitoids were compared with descriptions from the monograph [15]. All the parasitoids, emerged in the laboratory, belong to Hymenoptera. We have chosen for the study the most common species, Itoplectis maculator F., which parasitized about 12\% (137 from 296 emerged parasitoids) of the leaf roller pupae in our samples. The parasitoid specimens show contrast morphological polymorphism [14], which allows dividing them into genetically distinct groups.

Genetic variation in the I. maculator was studied using leg color of the adult specimens [14]: coloring of the hind leg femur with variants: "long black band" (Figure 2(a)), "short black band" (Figure 2(b)), "two spots" (Figure 2(c)), "one spot" (Figure 2(d)), and "zero" (Figure 2(e)); coloring of the tibia distal segment with variants: "light" (Figure 3(a)), "brown" (Figure 3(b)), and "black" (Figure 3(c)). The variants, which were no presented in all the samples, were excluded from the analysis.

Frozen specimens of this species were examined in respect to their heterogeneity in loci coding for esterase and nonspecific protein using allozyme-analysis [16]. These loci were both polymorphic in I. maculator, each including two alleles: $\mathrm{F}$ and $\mathrm{S}$.

Thorax and whole body lengths were measured in each of the morphologically assessed parasitoids under the binocular microscope MBS- 9 with precision $\pm 0.025 \mathrm{~mm}$. Manipulations with frozen parasitoids might change their body sizes. To avoid this we measured last right femur length in each of the frozen specimens prior to their homogenization for biochemical analysis. As the femur length relates to body size, it thus may reflect the specimen fitness component. The data 


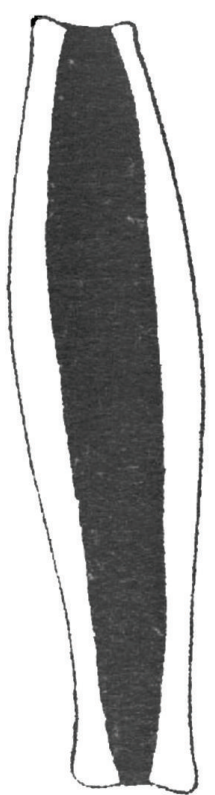

(a)

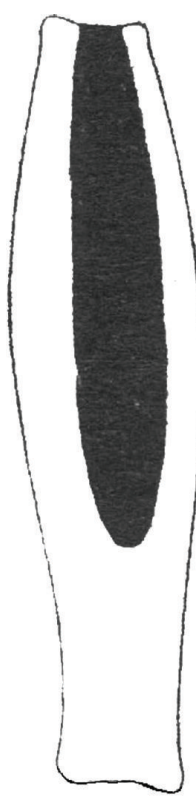

(b)

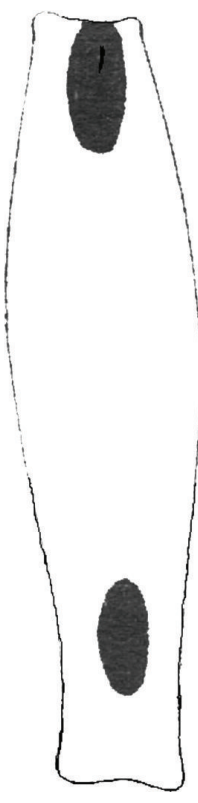

(c)

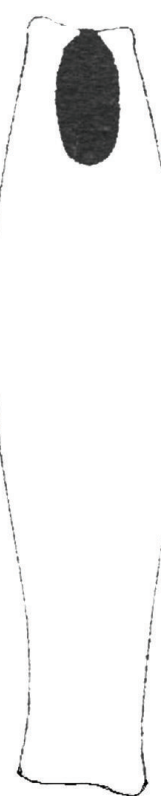

(d)

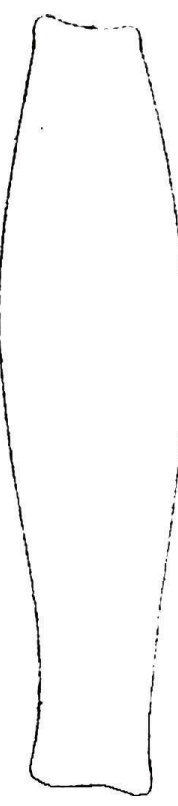

(e)

FIgURE 2: Variants of coloring of dorsal side of hind leg femur in I. maculator F. adults [14].

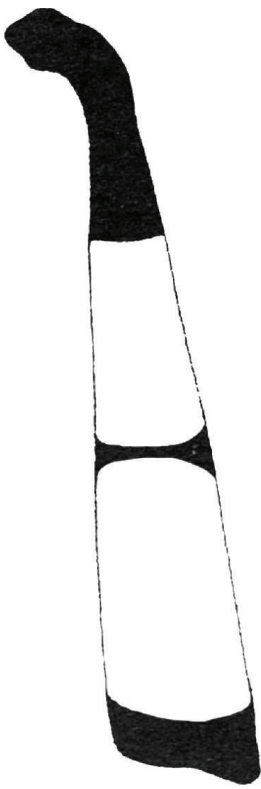

(a)

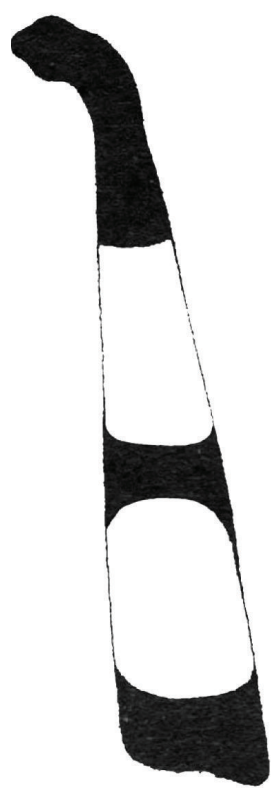

(b)

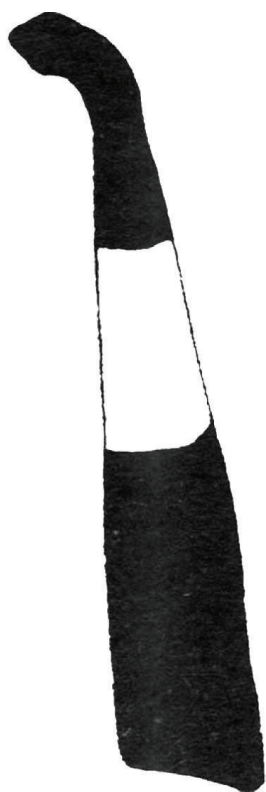

(c)

FIGURE 3: Variants of coloring of a tibia distal segment in I. maculator F. adults [14].

from males and females were analyzed separately because males and females differ in their average sizes.

RAPD-PCR analysis was performed using DNA sampled from each of the model trees. DNA was extracted from $10 \mathrm{mg}$ of fresh leaf tissue in accordance with standard method [17]. OPA-14 primer, TCTGTGCTGG (Operon Technologies, USA), was used for RAPD-PCR. Amplification was carried out under the following conditions: $95^{\circ} \mathrm{C}$ for $5 \mathrm{~min}$, followed by 45 cycles of $95^{\circ} \mathrm{C}$ for $1 \mathrm{~min}, 36^{\circ} \mathrm{C}$ for $1 \mathrm{~min}, 72^{\circ} \mathrm{C}$ for $2 \mathrm{~min}$, and final extension $72^{\circ} \mathrm{C}$ for $10 \mathrm{~min}$.

The amplification products were separated by electrophoresis in 1.8\% TBE agarose gel [17], stained with ethidium bromide and photographed under the UV light. DNA-markers M 100 (IsoGen, Moscow) including fragments with length of $100,200, \ldots, 900,1000 \mathrm{bp}$, were used as the molecular weight markers. 
TABLE 1: Results of two-way ANOVA on the parasitoid body lengths variation in dependence from parasitoid tibia phenotype and cremaster phenotype of the host insect pupa (see Figure 4).

\begin{tabular}{|c|c|c|c|c|}
\hline Source of variation & d.f. & Sum of squares & Mean squares & $F$ \\
\hline Leaf roller phenotype & 1 & 205.02 & 205.02 & 1.92 \\
\hline Parasitoid phenotype & 1 & 1.05 & 1.05 & 0.01 \\
\hline Interaction & 1 & 653.78 & 653.78 & $6.11^{*}$ \\
\hline Within & 28 & 2994.15 & 106.93 & \\
\hline Total & 31 & 3854.00 & & \\
\hline
\end{tabular}

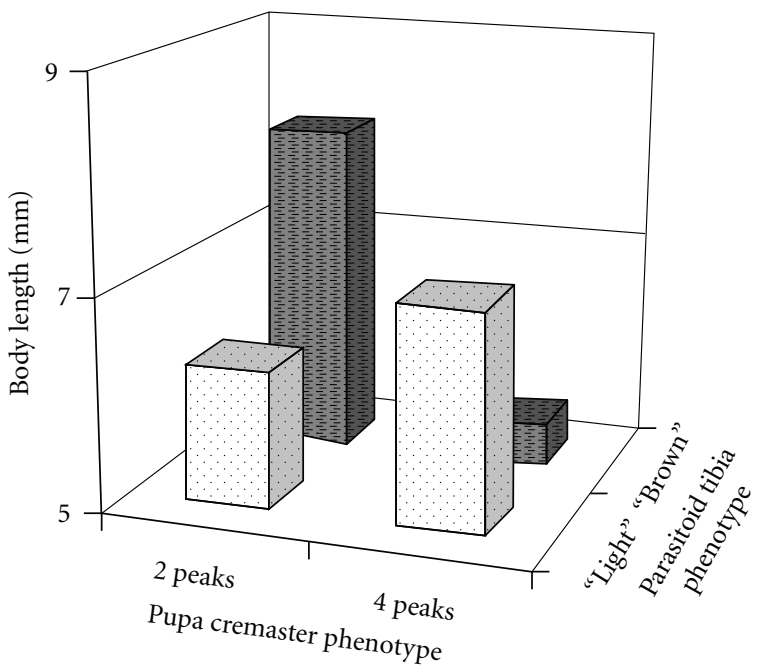

FIGURE 4: Body lengths of the I. maculator males in dependence on their phenotypes and phenotypes of their host insect pupae (results of two-way ANOVA in Table 1).

The results obtained were statistically processed using two-way ANOVA procedure. Total sample of the leaf roller pupae, from which the parasitoids emerged, was divided into groups in respect to their phenotypes. These groups were parasitized by $I$. maculator specimens distinct in their phenotypes or genotypes. Oak trees were divided into two groups in respect to presence or absence of one or another DNA fragment in their genotypes. These groups were inhabited by I. maculator specimens distinct in their phenotypes or genotypes. Thus, T. viridana phenotypes and I. maculator phenotypes, or Q. pubescent genotypes and $I$. maculator phenotypes were independent variables while $I$. maculator sizes were analyzed as a dependent variable. If parasitoids of one variant were presented in one leaf roller or oak group and absent in another one, then these parasitoids were excluded from the analysis in both the groups.

\section{Results}

3.1. Influence of Genetic Heterogeneity in Oak Leaf Roller Moth on the Fitness Components of Its Parasitoids. First step of the study was focused on the analysis of variation in $I$. maculator body sizes in respect to their morphological and

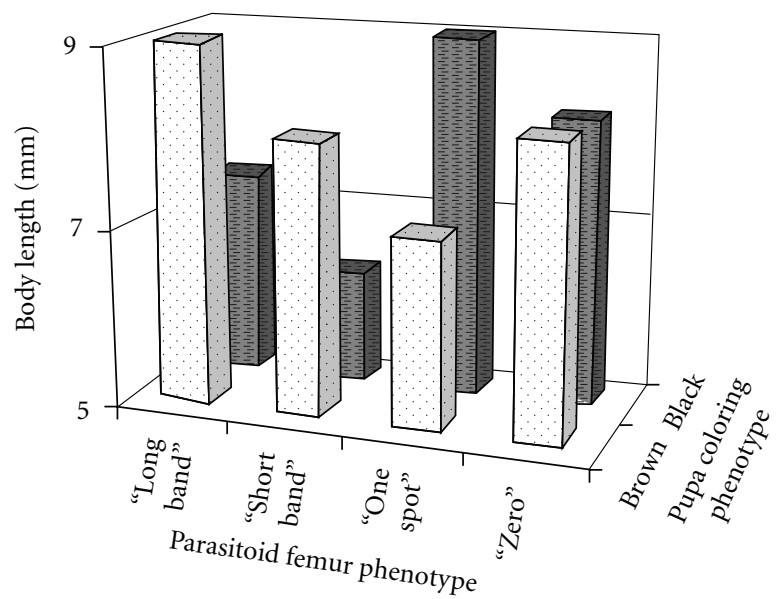

Figure 5: Body lengths of the I. maculator females in dependence on their phenotypes and phenotypes of their host insect pupae (results of two-way ANOVA in Table 2).

genetic variation and to the morphological variation in their host moths. Main attention was addressed to those cases when variation in parasitoid quantitative sign depended on the interaction between the genotypes of a parasitoid and its host insect. Statistically significant interactions show that the same genotype parasitoids may reach maximum sizes when developing in the moths carrying one genotype and remain small when developing in the moths which carry alternative genotype.

The I. maculator males with the "light" tibia coloring reached maximum body lengths when developing in the leaf roller pupae with four peaks at their cremasters, but remained small when developing in the leaf roller pupae with two peaks at their cremasters. Totally opposite picture was found for the I. maculator males with "brown" tibia coloring (Figure 4, Table 1). Variation in thorax lengths showed the same picture (interaction's $F=6.09 ; P<.05$ ).

The I. maculator females with alternatively colored femurs in the same manner differ in their sizes with respect to the host pupae coloring (Figure 5, Table 2). For thorax lengths interaction's $F=7.50(P<.01)$. Interaction of the factors contributes up to $45 \%$ to the total variation of the fitness-related signs in I. maculator females.

Except phenotypic variation these parasitoids were also described in respect to their genotypes in two allozyme loci, Est and Pt. Host insect phenotype influences dependence of 
TABLE 2: Results of two-way ANOVA on the parasitoid body lengths variation in dependence from the parasitoid femur phenotype and the host insect pupa coloring (see Figure 5).

\begin{tabular}{lcccc}
\hline Source of variation & d.f. & Sum of squares & Mean squares & $F$ \\
\hline Leaf roller phenotype & 1 & 53.52 & 53.52 & 1.00 \\
Parasitoid phenotype & 3 & 264.32 & 88.11 & 1.64 \\
Interaction & 3 & 789.79 & 263.26 & $4.90^{*}$ \\
Within & 28 & 1503.04 & 53.68 & \\
\hline Total & 35 & 2610.67 & &
\end{tabular}

TABLE 3: Results of two-way ANOVA on the parasitoid femur lengths variation in dependence from the parasitoid two-locus genotype (number of heterozygous loci) and the host insect pupa coloring (see Figure 6).

\begin{tabular}{|c|c|c|c|c|}
\hline Source of variation & d.f. & Sum of squares & Mean squares & $F$ \\
\hline Leaf roller phenotype & 1 & 0.01 & 0.01 & 0.05 \\
\hline Parasitoid genotype & 2 & 0.03 & 0.01 & 0.14 \\
\hline Interaction & 2 & 1.02 & 0.51 & $4.92^{*}$ \\
\hline Within & 40 & 4.15 & 0.10 & \\
\hline Total & 45 & 5.21 & & \\
\hline
\end{tabular}

the parasitoid sizes from number of heterozygous combinations in their two-locus genotypes. Homozygotes were large when developing in the brown-colored host insect pupae and small when developing in those black colored while two-locus heterozygotes showed quite an opposite trend (Figure 6, Table 3). Interaction contributes up to $49 \%$ to the total variation of the fitness-related signs in I. maculator males.

As the parasitoid femur length relate to body size, and body sizes relates to specimen fitness, we may say, for example, that homozygous parasitoids survive better and produce more offspring when they develop in brown than in black host pupae. If this is the case, then we should find statistic associations between corresponding genotypes of the parasitoid and its host insect. Significant association was found only for the I. maculator "light" tibia phenotype and "four-peak" cremaster phenotype in the T. viridana pupae $\left(r=0.43 ;\right.$ d.f. $\left.=1 ; \chi^{2}=5.88 ; P<.05\right)$.

\subsection{Influence of Genetic Heterogeneity in Oaks on the Fitness} Components of I. maculator. RAPD-PCR analysis of oak leaves with OPA 14 primer gave a range of DNA fractions (Figure 7). Model trees exhibit wide polymorphism on the obtained RAPD-markers. Individual spectrum could contain from 4 to 12 amplified DNA fragments.

Two-way ANOVA was applied to study how the I. maculator sizes varied in respect to their phenotypes and genotypes of the oaks, at which their host insects had been fed. In this case we also have found an interaction between studied factors. The I. maculator males with "black" tibia phenotype were small on the oak trees with OPA 14-4 DNA fraction in their RAPD-PCR spectrums and reached maximum sizes on the trees without that fraction. Alternative phenotype showed opposite trend (Figure 8, Table 4). Statistics for body lengths was some lower the $95 \%$ confidence level while tho-

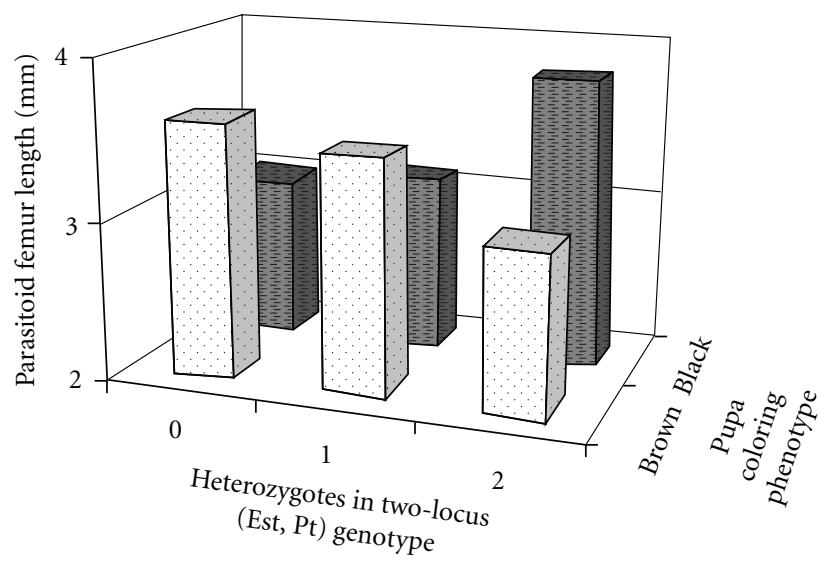

FIGURE 6: Femur lengths in the I. maculator males in dependence on their two-locus (Est, Pt) genotype (number of heterozygous loci) and phenotypes of their host insect pupae (results of two-way ANOVA in Table 3).

rax lengths showed significant results. The OPA 14-5 DNA fraction in oak leaves also influence mean sizes of the parasitoids with alternative tibia phenotypes (Figure 9, Table 5).

Statistically significant association was found only for the "black" tibia phenotype of the parasitoid, which was frequently observed in the oak leaf roller pupae from oaks without the OPA 14-4 DNA fraction in their RAPD-PCR spectrums $\left(r=0.25\right.$; d.f. $\left.=1 ; \chi^{2}=4.44 ; P<.05\right)$.

\section{Discussion}

In this paper, we show dependence of parasitoid sizes not only from their genotypes, but also from phenotypes of host pupae, which they parasitize, and from genotypes of oak trees, on which the hosts have developed. Body size of an 


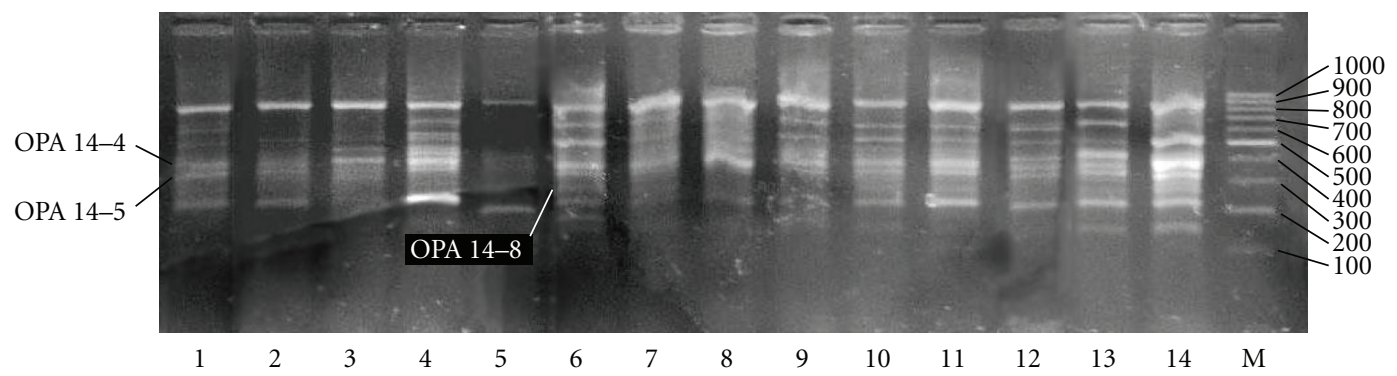

FIGURE 7: Individual electrophoretic spectrums of amplified DNA fragments from leaves of 14 model oaks with primer OPA 14; M: molecular markers (100-1000 bp).

TABLE 4: Results of two-way ANOVA on the parasitoid thorax lengths variation in dependence on the parasitoid tibia phenotype and genotypes of oaks (presence or absence of the OPA 14-4 DNA fraction; see Figure 8).

\begin{tabular}{lcccc}
\hline Source of variation & d.f. & Sum of squares & Mean squares & 1.23 \\
\hline Oak genotype & 1 & 1.23 & 0.85 & 0.22 \\
Parasitoid phenotype & 1 & 0.85 & 28.27 & 0.15 \\
Interaction & 1 & 28.27 & 5.69 & \\
Within & 28 & 159.37 & & \\
\hline Total & 31 & 189.72 &
\end{tabular}

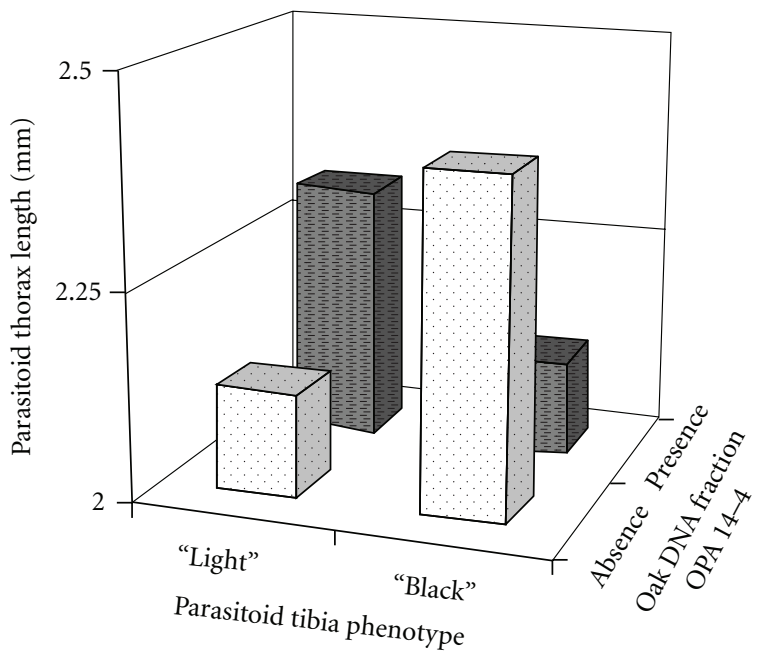

Figure 8: Thorax lengths in the I. maculator males in dependence on their phenotypes and genotypes of oaks (presence or absence of the OPA 14-4 DNA fraction) on which their host insect pupae were developed (results of two-way ANOVA in Table 4).

insect, as a rule, relates to its fitness $[11,12]$. This is true both for insect viability and reproduction, because females choose large males as their mates and ignore small males.

Parasitoid size usually relates to the size of its host insect and this is also true for oak leaf roller moth and its parasitoids, but the correlation is not strong with coefficients ranged between 0.2 and 0.4 [14]. Pupa size, thus, is not the main factor influencing size of a parasitoid developing in it. Insect size usually relates to its fitness. In our case this means that, for example, homozygous parasitoids survive better and

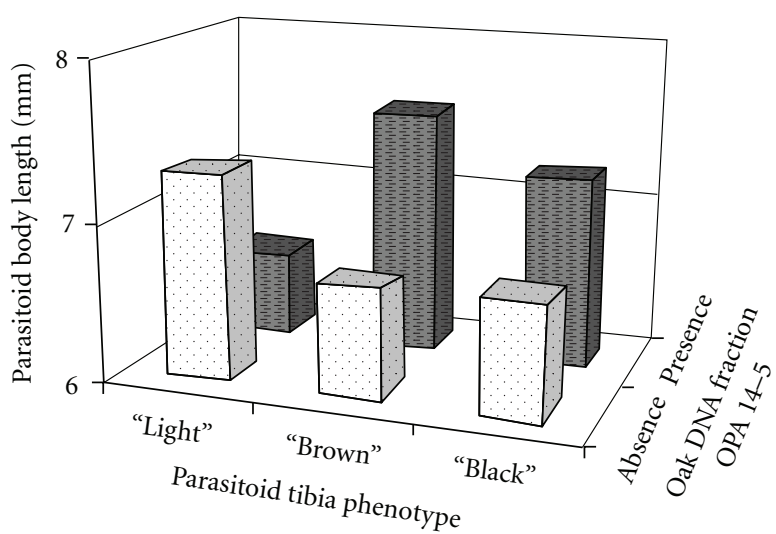

Figure 9: Body lengths of the I. maculator males in dependence on their phenotypes and genotypes of oaks (presence or absence of the OPA 14-5 DNA fraction) on which their host insect pupae were developed (results of two-way ANOVA in Table 5).

produce more offspring when they developed in brown than in black host pupae.

We may, thus, say that oak genotype and phenotype of oak leaf roller pupa, which has develop on this tree, influence fitness of a parasitoid that parasitizes this pupa. In other words, genotypes of host plant and host herbivore drive the parasitoid selection, changing genotype frequencies in its population. By this reason, genotype frequencies become related in three links of food chain. Earlier we have detected this as associations between genotypes or phenotypes of oaks and moths [18].

Found associations represent ties among the gene pools of populations, interacting in a community. As we have 
TABLE 5: Results of two-way ANOVA on the parasitoid thorax lengths variation in dependence on the parasitoid tibia phenotype and genotypes of oaks (presence or absence of the OPA 14-5 DNA fraction; see Figure 9).

\begin{tabular}{lcccc}
\hline Source of variation & d.f. & Sum of squares & Mean squares & $F$ \\
\hline Oak genotype & 1 & 30.12 & 30.12 & 0.65 \\
Parasitoid phenotype & 2 & 23.50 & 11.75 & 0.25 \\
Interaction & 2 & 396.67 & 198.33 & $4.26^{*}$ \\
Within & 40 & 1863.37 & 46.58 & \\
\hline Total & 45 & 2313.65 & & \\
${ }^{*} P<.05$. & & &
\end{tabular}

elements, gene pools, and ties among them, we may say about some system, "genetic" system of a community. M. A. Holubets $[19,20]$ heuristically described this system as ecosystem "memory," regulatory, informative subsystem driving ecosystem functioning, and called it genoplast. As genoplast arises on the base of selective processes within each of the interacting populations, its explanation requires no introduction of such categories as "ecosystem selection" or "ecosystem heritability" $[3,4]$. Of course, as heritability is peculiar to each of the individuals included in a community, there should be some succession among the past, present and future states of the community. This ecosystem succession is equivalent to the heritability at the level of individuals, and may mimic it in the case, when species participants of a community strongly differ in their life cycle durations. Genoplast is the next hierarchy level after population gene pools. It arises from interactions among the representatives of different species, and its succession integrates individual heritabilities in the same manner as pressure of a gas integrates velocities of the molecules it consists of.

The concept of "extended phenotype," which some investigators put into the base of ecosystem genetics, is very close to the concept of individual and species consortia, peculiar to the East-Europe ecological tradition [14, 21]. Individual consortium is an elementary ecosystem, which consists of central organism (as a rule, large organism such as tree or mammal, e.g.) and all the other organisms living in, on, and around it. Population and species consortia integrate individual consortia of population and species representatives correspondingly Genoplast, thus, seems to be more reasonable candidate as a matter of ecosystem genetics study than "extended phenotype."

Ecologists often conclude that intrapopulation genetic variation very little contributes to the total dynamics of stable ecosystems. But this stability may be a function of those genetic variations, which occur within each of the populations and interact across them. At the same time, genetic hypotheses found their places among others, explaining population numerical dynamics $[22,23]$.

Sexual selection, influencing mating system, evokes rapid genetic changes and may have dramatic impact on the population numbers [12]. With that, sexual selection presupposes that no each of the population members has a chance for reproduction and these "losers" differ from "winners" in their genotypes. Thus, genetic lows influence the "decision," how many population members could contribute to the offspring quantity and quality.
Strength of genotype-genotype interactions among the representatives of different species in the ecological community may be critical for answering the question: whether the genetic-ecological interplay is really sufficient for understanding of ecosystem functioning. Strong impact of interaction between genotypes or phenotypes of different species representatives, reaching $49 \%$ from total variation, on the fitness of one of them argues for incorporation of genetics into ecological explanations.

\section{Acknowledgment}

The Authors would like to thank the anonymous reviewers whose valuable suggestions allowed the improvement of the paper.

\section{References}

[1] J. P. Collins, "Evolutionary ecology and the use of natural selection in ecological theory," Journal of the History of Biology, vol. 19, no. 2, pp. 257-288, 1986.

[2] C. Neuhauser, D. A. Andow, G. E. Heimpel, G. May, R. G. Shaw, and S. Wagenius, "Community genetics: expanding the synthesis of ecology and genetics," Ecology, vol. 84, no. 3, pp. 545-558, 2003.

[3] T. G. Whitham, W. P. Young, G. D. Martinsen et al., "Community and ecosystem genetics: a consequence of the extended phenotype," Ecology, vol. 84, no. 3, pp. 559-573, 2003.

[4] J. K. Bailey, S. C. Wooley, R. L. Lindroth, and T. G. Whitham, "Importance of species interactions to community heritability: a genetic basis to trophic-level interactions," Ecology Letters, vol. 9, no. 1, pp. 78-85, 2006.

[5] R. E. Ricklefs, "Genetics, evolution, and ecological communities," Ecology, vol. 84, no. 3, pp. 588-591, 2003.

[6] P. J. Morin, "Community ecology and the genetics of interacting species," Ecology, vol. 84, no. 3, pp. 577-580, 2003.

[7] F. E. Clements, "Nature and structure of the climax," Journal of Ecology, vol. 24, no. 1, pp. 252-284, 1936.

[8] M. J. Dunbar, "The evolution of stability in marine environments," The American Naturalist, vol. 94, pp. 129-136, 1960.

[9] H. A. Gleason, "The individualistic concept of the plant association," Bulletin of the Torrey Botanical Club, vol. 53, pp. 7-26, 1926.

[10] R. H. Whittaker, "Dominance and diversity in land plant communities," Science, vol. 147, no. 3655, pp. 250-260, 1965.

[11] W. B. Watt, P. A. Carter, and K. Donohue, "Females' choice of "good genotypes" as mates is promoted by an insect mating system," Science, vol. 233, no. 4769, pp. 1187-1190, 1986. 
[12] A. P. Simchuk, A. V. Ivashov, and V. A. Companiytsev, "Genetic patterns as possible factors causing population cycles in oak leafroller moth, Tortrix viridana L.," Forest Ecology and Management, vol. 113, no. 1, pp. 35-49, 1999.

[13] A. V. Yablokov, Phenetika, Nauka, Moscow, Russia, 1980.

[14] A. V. Ivashov, Consortive relations of the oak leaf roller moth (Tortrix viridana L.): theoretic and applied aspects, Dissertation, Taurida National University, Simferopol, Ukraine, 2001.

[15] M. D. Zerov, A. G. Kotenko, and K. Y. Seregina, Eds., Entomophagans of the Oak Leaf Roller and Gypsy Moth in the South-East of European USSR, Naukova Dumka, Kiev, Ukraine, 1989.

[16] O. Gaal, G. Medjeski, and L. Veretskey, Electrophoresis in the Separation of Biological Macromolecules, Mir, Moscow, Russia, 1980.

[17] J. Sambrook, E.F. Fritisch, and T. Maniatis, Molecular Cloning: Laboratory Manual, Cold Spring Harbour University Press, New York, NY, USA.

[18] A. P. Simchuk, "Influence of genetic variation of oaks as forage substrate on the fitness components of Tortrix viridana L.", Cytology and Genetics, vol. 42, no. 1, pp. 45-52, 2008.

[19] M. A. Holubets, Actual Questions of Ecology, Naukova Dumka, Kiev, Ukraine, 1982.

[20] M. A. Holubets, Ekosistemologiya (Ecosystematics), Polli Publishers, L'viv, Ukraine, 2000.

[21] V. V. Mazing, "Consortia as elements of the ecosystem functional structure," Trudi Moskovskogo Oschestva Ispitatelej Prirodi, vol. 27, pp. 117-126, 1966.

[22] D. Pimentel and R. Al-Hafidh, "Ecological control of a parasite population by genetic evolution in the parasite-host system," Annals of the Entomological Society of America, vol. 58, no. 1, pp. 1-6, 1965.

[23] D. Chitty, "Predicting qualitative changes in insect populations," in Proceedings of the 12th International Congress of Entomology, pp. 384-386, London, UK, July 1964. 

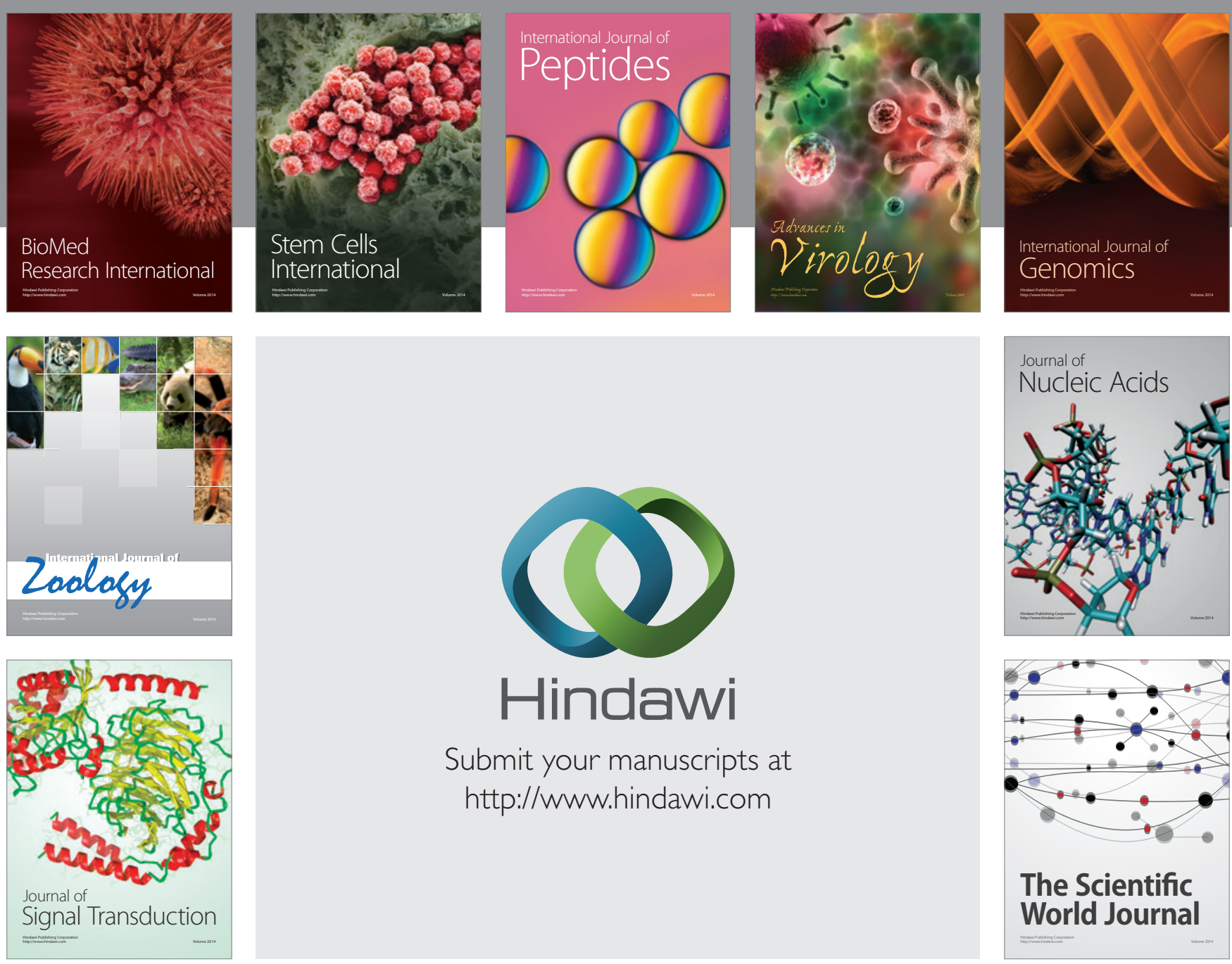

Submit your manuscripts at

http://www.hindawi.com
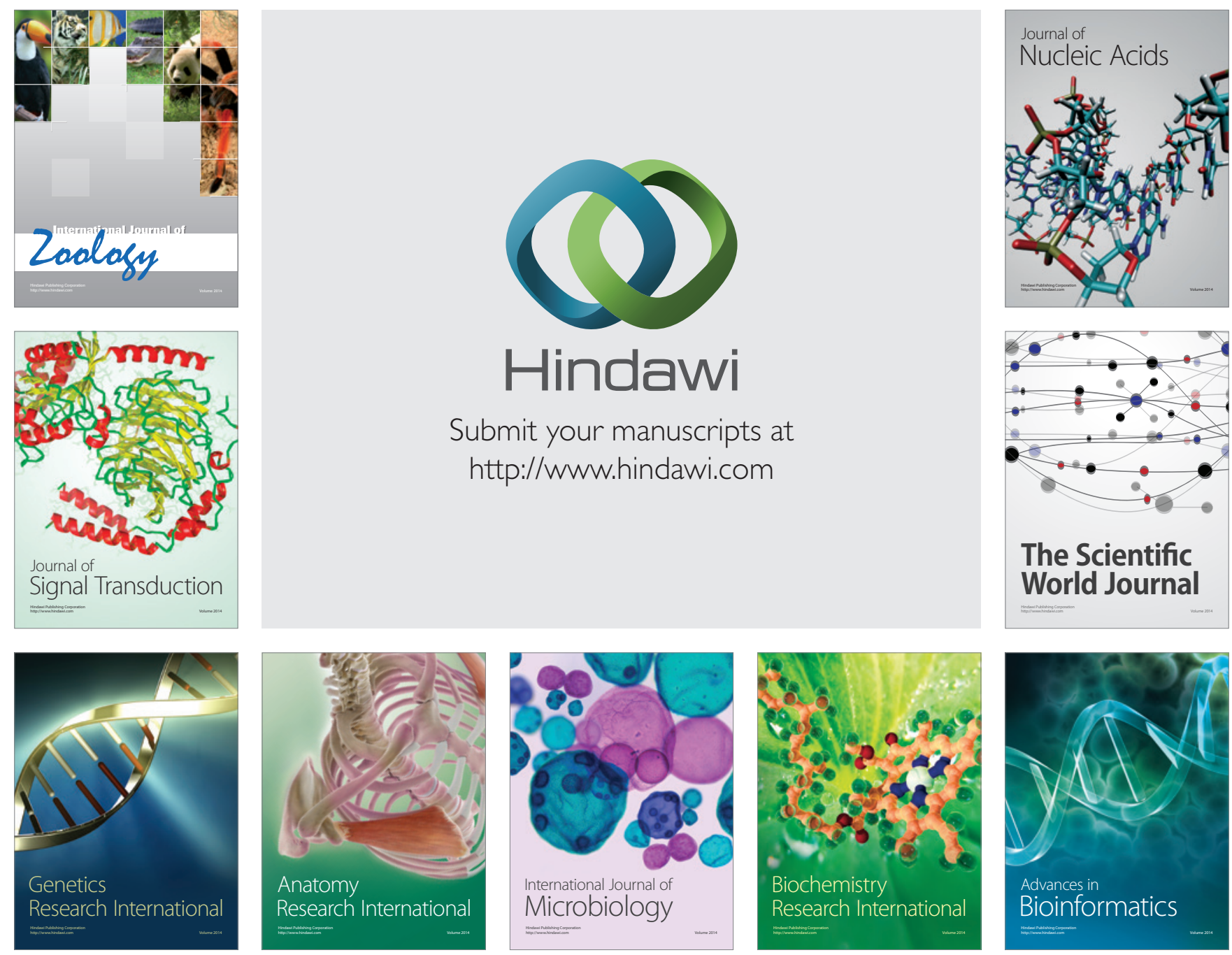

The Scientific World Journal
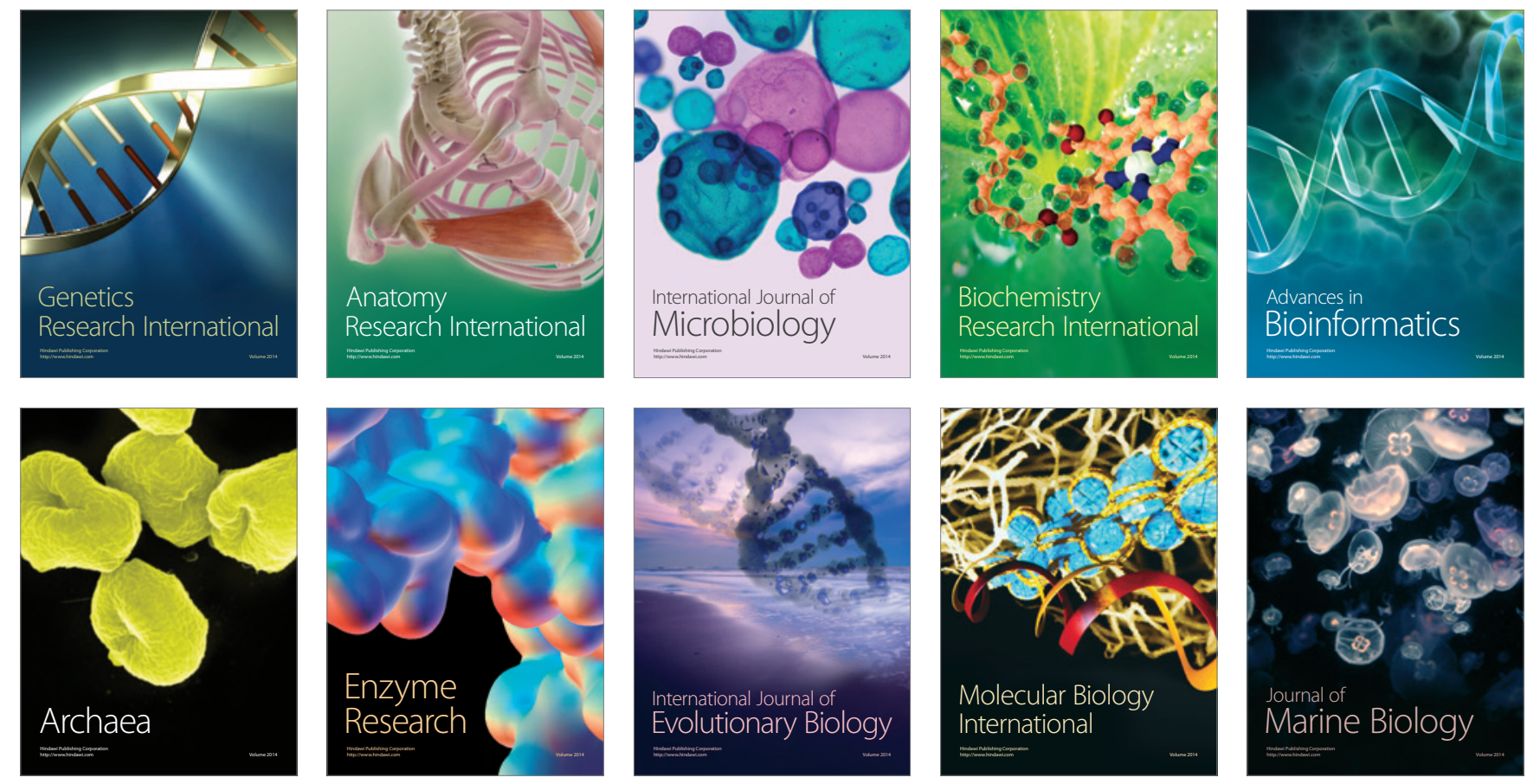